Рекомендована д. фрармац. наук, профр. В. А. Георгіянц

УДК 547.789:542.91:615.015.4

DOI 10.11603/2312-0967.2017.4.8340

\title{
РОЗРОБКА ТА ВАЛІДАЦІЯ МЕТОДИКИ СПЕКТРОФОТОМЕТРИЧНОГО КІЛЬКІСНОГО ВИЗНАЧЕННЯ ДИЛТІАЗЕМУ В ЛІКАРСЬКИХ ФОРМАХ
}

\author{
() М. І. Сулима ${ }^{1}$, В. В. Огурцов ${ }^{1}$, Ю. М. Жук², С. О. Васюк ${ }^{2}$ \\ Львівський національний медичний університет імені Данила Галицького ${ }^{1}$ \\ Запорізький державний медичний університет² \\ Sumarta145@gmail.com
}

\begin{abstract}
Мета роботи. Розробка методів контролю якості, зокрема, спектрофотометричного визначення кількісного вмісту дилтіазему в лікарських фрормах «Діакордін 60» та «Діакордін 90 Ретард» на основі реакції з бромкрезоловим зеленим, а також валідація розроблених методик.

Матеріали і методи. Об'єкти дослідження - таблетки «Діакордін 60» (Zentiva у складі САНОФІ, Чеська Республіка, серія 3010117) та таблетки «Діакордін 90 Ретард» (Zentiva у складі САНОФІ, Чеська Республіка, серія 3510317). Реагенти і розчинники: стандартний зразок дилтіазему, бромкрезоловий зелений, ацетон.

Аналітичне обладнання: спектрофотометр Specord 200, ваги електронні ABT-120-5DM, ультразвукова баня ELMASONICE60 H.

Результати й обговорення. Розроблено методику спектрофотометричного визначення кількісного вмісту дилтіазему в лікарських фрормах «Діакордін 60» та «Діакордін 90 Ретард» на основі реакції з бромкрезоловим зеленим. Стехіометричні співвідношення реагуючих компонентів «дилтіазем - БКЗ», одержані методами неперервних змін та методом насичення, повністю узгоджуються між собою та становлять 1:1. За такими валідаційними характеристиками, як лінійність, прецизійність, правильність та робасність розроблена методика $€$ коректною і може бути використана у відділах технічного контролю хіміко-срармацевтичних підприємств.

Висновки. У результаті роботи встановлено, що дилтіазем реагує з БКЗ у середовищі ацетону за кімнатної температури з утворенням забарвленого продукту з максимумом світлопоглинання при 408 нм. Досліджувана реакція $€$ високочутливою: молярний коефіцієнт світлопоглинання становить 11547, а відкривальний мінімум 1,79 мкг/мл.

Доведено, що за такими валідаційними характеристиками, як лінійність, прецизійність, правильність та робасність розроблена методика є коректною і може бути використана у відділах технічного контролю хіміко-фрармацевтичних підприємств.
\end{abstract}

Ключові слова: дилтіазем; бромкрезоловий зелений; ацетон; спектрофотометричне визначення.

Вступ. Дилтіазем - лікарський засіб із групи блокаторів кальцієвих каналів, похідне бензотіазепіну, був синтезований ще у 1971 році. Однак і на сьогодні він залишається представником даної групи, що найбільш широко використовується для лікування серцево-судинних захворювань.

У літературі описано чимало методик кількісного визначення дилтіазему як у чистому вигляді, так і у складі лікарських фрорм. Серед них переважають хроматограсрічні [1-4] та спектрофротометричні методики [5-9]. Незважаючи на появу такого засобу аналізу лікарських препаратів, як високоефективна рідинна хроматограсрія, спектрофотометричні методи зберігають важливе місце в фрармакопейному аналізі.

Тому метою роботи стала розробка методів контролю якості, зокрема, спектрофротометричне визначення кількісного вмісту дилтіазему в лікарських фрормах «Діакордін 60» та «Діакордін 90 Ретард» на основі реакції з бромкрезоловим зеленим, а також валідація розроблених методик.

Матеріали і методи. Об'єкти дослідження - таблетки «Діакордін 60» (Zentiva у складі САНОФІ, Чеська Республіка, серія 3010117) та таблетки «Діакордін 90 Ретард» (Zentiva у складі САНОФІ, Чеська Республіка, серія 3510317).

Реагенти і розчинники: стандартний зразок дилтіазему, бромкрезоловий зелений, ацетон.

Аналітичне обладнання: спектрофотометр Specord 200, ваги електронні АВT-120-5DM, ультразвукова баня ELMASONICE60 H.

Загальна методика визначення дилтіазему

Приготування розчину порівняння дилтіазему: 0,03 г дилтіазему поміщають у мірну колбу ємкістю 100,00 мл, розчиняють в ацетоні та доводять ацетоном до позначки, перемішують.

Приготування компенсаційного розчину: 1,00 мл $1 \%$ розчину БКЗ в ацетоні переносять у мірну колбу

ISSN 2312-0967. Pharmaceutical review. 2017. № 4 


\section{Analysis of drugs}

на 10,00 мл, доводять ацетоном до позначки та перемішують.

Аліквотну частину дилтіазему (0,2072-0,3729 мг) поміщають у мірну колбу ємкістю 10,00 мл, додають 1,00 мл 1\% розчину БКЗ в ацетоні та доводять ацетоном до позначки, перемішують. Абсорбцію отриманого розчину вимірюють на фоні компенсаційного розчину за аналітичної довжини хвилі 408 нм на спектрофотометрі в кюветі з товщиною поглинаючого шару $1 \mathrm{~cm}$.

\section{Визначення дилтіазему в таблетках}

Точну наважку ретельно розтертої таблеткової маси (близько 0,1451 г) «Діакордін 60» та (близько 0,1483 г) «Діакордін 90 Ретард» переносять у мірну колбу на 100,00 мл, доводять ацетоном до позначки, озвучують в ультразвуковій бані протягом 1 хв. Після цього розчин фрільтрують через паперовий беззольний фрільтр («Синя стрічка»), відкидаючи перші порції фрільтрату. 3 наступних порцій фрільтрату беруть 1,00 мл розчину, переносять у мірну колбу ємкістю 10,00 мл, додають 1,00 мл розчину БК3, доводять ацетоном до позначки та вимірюють абсорбцію отриманих розчинів на фоні компенсаційного розчину за аналітичної довжини хвилі 408 нм. Паралельно проводять дослід з 1,00 мл розчину порівняння дилтіазе- 0 , му. Розрахунок вмісту діючої речовини проводять за загальноприйнятою формулою.

Результати й обговорення. Для розробки методики кількісного визначення дилтіазему у складі лікарських фрорм на основі реакції з сульфоорталеїновими барвниками було вивчено наступні чинники, які можуть впливати на повноту та швидкість перебігу реакції: природа та склад розчинника, природа та -0,2 кількість реагентів, швидкість реакції та стабільність аналізованих розчинів у часі.

При виборі розчинника для даної реакції враховували розчинність дилтіазему та реагентів і оптимальне значення оптичної густини забарвлених розчинів. Під час вибору реагенту для розробки методик кількісного визначення дилтіазему порівнювали спектри поглинання продуктів реакцій з найпоширенішими сульфоорталеїновими барвниками (БКЗ, БКП та БТС). Основним критерієм вибору реагенту було максимальне значення оптичної густини продукту реакції. Отже, експериментальним шляхом встановлено, що реакція перебігає у середовищі ацетону за кімнатної температури з використанням БКЗ у якості реагенту з утворенням забарвленого продукту реакції 3 максимумом світлопоглинання при 408 нм (рис. 1).

На наступному етапі дослідження було визначено стабільність аналізованих розчинів у часі. Для цього вимірювали оптичну густину отриманого розчину в оптимальних умовах протягом 40 хв 3 інтервалом по 5 хв. Було встановлено, що досліджувані розчини стабільні протягом щонайменше 40 хв.
Для визначення стехіометричних коеріцієнтів між дилтіаземом та БКЗ було використано метод неперервних змін (метод ізомолярних серій) та метод насичення (метод молярних співвідношнь) [10].

В основі методу неперервних змін лежить визначення співвідношень ізомолярних концентрацій реагуючих речовин, що відповідає максимальному виходу сполук, що утворюються в результаті реакції. При цьому крива залежності виходу продукту реакції від складу розчину характеризується екстремальною точкою, положення якої пов'язане зі стехіометричними коефіцієнтами реагуючих речовин (рис. 2).

У методі насичення точка перегину на кривій насичення відповідає відношенню концентрацій реагуючих сполук та дорівнює стехіометричному коеоріцієнту компонента, концентрація якого змінювалася (рис. 3).



Рис. 1. Спектри поглинання продукту реакції дилтіазему з БКЗ (1), розчину БКЗ (2), розчину дилтіазему (3).

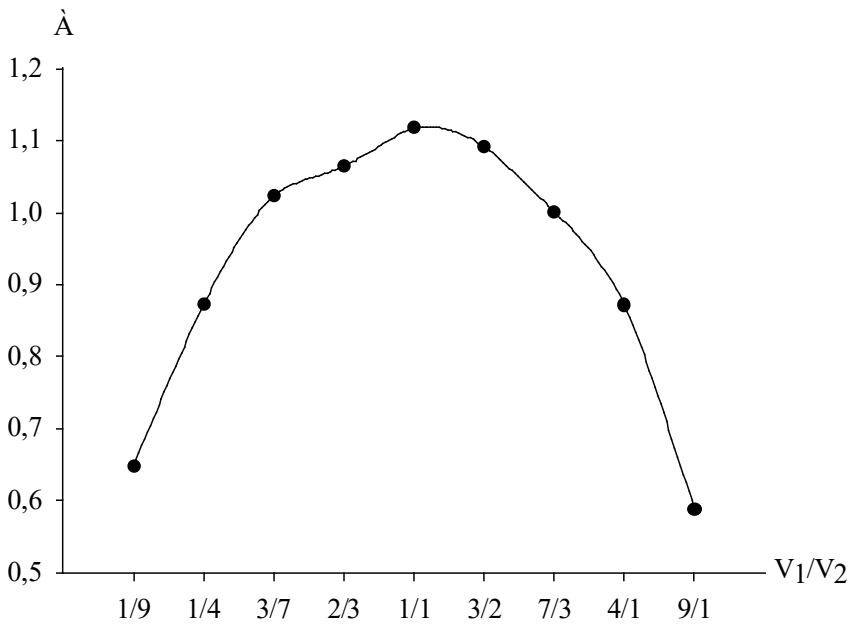

Рис. 2. Грасрік залежності величини оптичної густини від складу ізомолярного розчину $\left(\mathrm{C}_{1}-0,0075 \mathrm{M}\right.$ розчин БКЗ, $\mathrm{C}_{2}-0,0075 \mathrm{M}$ розчин дилтіазему).

ISSN 2312-0967. Фармацевтичний часопис. 2017. № 4 


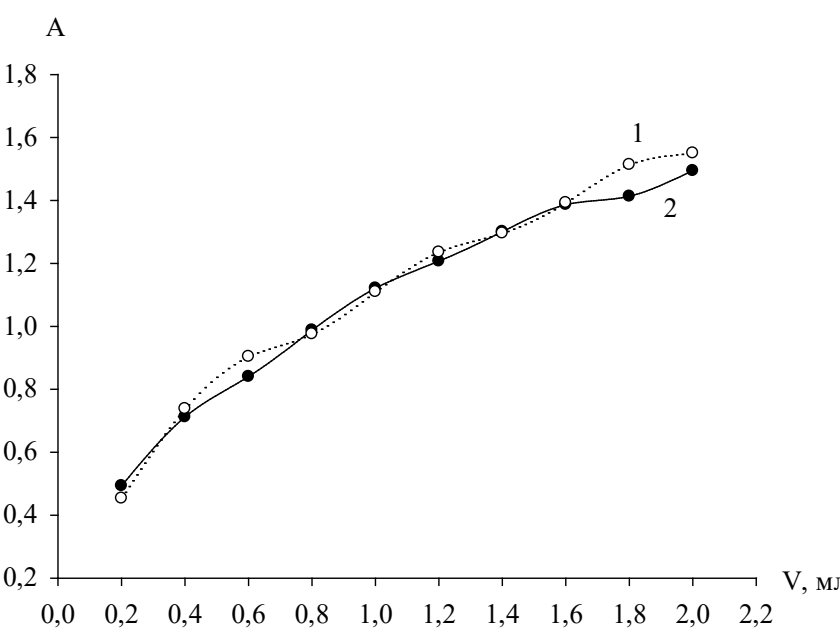

Рис. 3. Криві насичення: 1 - БКЗ при постійній концентрації дилтіазему (1,00 мл 0,0075 М розчину); 2 - дилтіазему при постійній концентрації БКЗ (1,00 мл 0,0075 М розчину).

Стехіометричні співвідношення реагуючих компонентів «дилтіазем - БКЗ», одержані методами неперервних змін та методом насичення, повністю узгоджуються між собою і становлять 1:1.

Визначення валідаційних характеристик

Згідно з вимогами ДФУ [11] для оцінки коректності методики при виконанні аналізу в іншій лабораторії було розраховано загальну невизначеність методики аналізу.

Прогнозована повна невизначеність результатів аналізу не повинна перевищувати максимально допустиму невизначеність результатів аналізу $\max _{\text {As. }}$
Розрахунки невизначеності пробопідготовки проводили, враховуючи вимоги ДФУ до гранично допустимих похибок для мірного посуду, вагів та приладів (табл. 1).

Для того, щоб аналітична методика гарантувала достовірні та точні результати аналізу, передбачена процедура валідації аналітичних методик. Згідно 3 ДФУ запропоновані методики кількісного визначення дилтіазему були перевірені за такими валідаційними характеристиками, як лінійність, діапазон застосування, точність, правильність та робасність [11].

Лінійність та діапазон застосування методики

Лінійність визначали в межах концентрацій, в яких спостерігається підпорядкування основному закону світлопоглинання, а саме 2,072-3,729 мг/100 мл. Для отримання розчинів 3 відомою концентрацією розводили стандартний розчин дилтіазему та проводили визначення за загальною методикою. За отриманими даними будували графрік залежності оптичної густини від концентрації аналізованого розчину (рис. 4).

Як видно з даних, наведених у таблиці 2, методика лінійна у всьому зазначеному діапазоні концентрацій. Отже, діапазон застосування методики складає 72-128 \% від номінального вмісту дилтіазему в лікарському засобі.

Прецизійність

Прецизійність методики визначали на рівні збіжності. Для цього проводили дев'ять паралельних визначень (три наважки/три повтори). За отриманими результатами розраховували метрологічні характеристики (табл. 3). В обох випадках однобічний довірчий інтервал $\Delta \mathrm{x}$ не перевищує максимально допустиму невизначеність аналізу, тому методика є точною на рівні збіжності.

Таблиця 1. Розрахунок невизначеності пробопідготовки для кількісного визначення таблеток «Діакордін 60»

\begin{tabular}{|l|c|c|}
\hline \multicolumn{1}{|c|}{ Операція пробопідготовки } & $\begin{array}{c}\text { Параметр } \\
\text { розрахункової } \\
\text { формули }\end{array}$ & Невизначеність, \% \\
\hline \multicolumn{2}{|c|}{ розчин порівняння } \\
\hline 1) взяття наважки РС3 дилтіазему & $m_{0}$ & 0.2 мг/30 мг × 100\%= 0,67 \\
\hline 2) доведення до об'єму в мірній колбі ємністю 100,00 мл & 100 & 0,12 \\
\hline 3) взяття аліквоти піпеткою 1,00 мл & 1 & 0,6 \\
\hline 4) доведення до об'єму в мірній колбі ємністю 10,00 мл & 10 & 0,5 \\
\hline \multicolumn{2}{|c|}{ випробовуваний розчин } \\
\hline 5) взяття наважки таблеток & $m_{1}$ & 0,2 мг/145,1 мг × $100 \%=0,14$ \\
\hline 6) доведення до об'єму в мірній колбі ємністю 100,00 мл & 100 & 0,12 \\
\hline 7) взяття аліквоти піпеткою 1,00 мл & 1 & 0,6 \\
\hline 8) доведення до об'єму в мірній колбі ємністю 10,00 мл & 10 & 0,5 \\
\hline
\end{tabular}

$$
\Delta_{S P}=\sqrt{0,67^{2}+0,12^{2}+0,6^{2}+0,5^{2}+0,14^{2}+0,12^{2}+0,6^{2}+0,5^{2}}=1,31 \%
$$

Повна невизначеність аналітичної методики:

$$
\boldsymbol{\Delta}_{A S}=\sqrt{\Delta_{S P}^{\mathbf{2}}+\Delta_{F A O}^{2}}=\sqrt{1,3 \mathbf{1}^{2}+0,7 \mathbf{0}^{2}}=1,49 \% \leq \max _{A S}=3,2 \%
$$

ISSN 2312-0967. Pharmaceutical review. 2017. № 4 
Аналіз лікарських препаратів

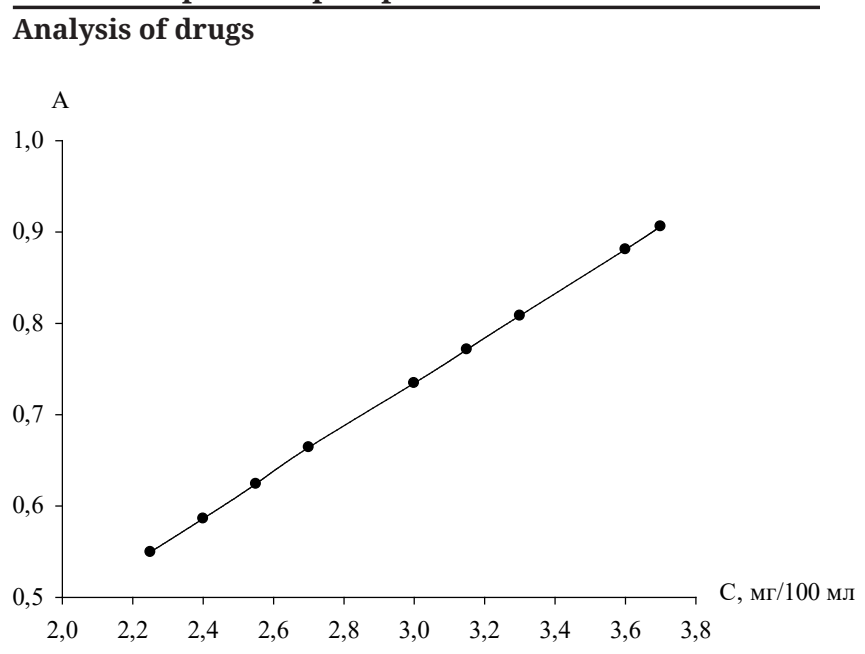

Рис. 4. Грасрік залежності оптичної густини від концентрації дилтіазему.

\section{Правильність}

Правильність методик було визначено методом добавок. Для цього до трьох рівних проб лікарської фрорми додавали різну кількість розчину порівняння дилтіазему та аналізували тричі. Як видно 3 даних таблиці 4, розраховані критерії практичної незначущості для обох лікарських фрорм не перевищують максимально допустиму невизначеність аналізу.

\section{Робасність}

Робасність $€$ показником надійності методики при ії̈ використанні у зазначених умовах.

Оцінку робасності було проведено на стадії розробки методики. Для цього було вивчено вплив зовнішніх фракторів, які можуть впливати на величину оптичної густини: стабільність аналізованих розчинів у часі та кількість доданих реагентів.

Таблиця 2. Оптичні характеристики та основні параметри лінійної залежності реакції дилтіазему з БКЗ

\begin{tabular}{|c|c|}
\hline Молярний показник поглинання, $\varepsilon$ & 11547 \\
\hline Коефріцієнт Сендела, $\mathrm{W}_{\mathrm{s}}$ & 0,0359 \\
\hline Відкривальний мінімум, Cmin (мкг/мл) & 1,79 \\
\hline Рівняння лінійної регресії & $Y=b X+a$ \\
\hline 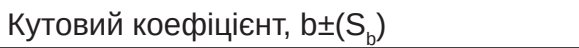 & $0,2453 \pm(0,0010)$ \\
\hline Вільний член лінійної регресії, $\mathrm{a} \pm\left(\mathrm{S}_{\mathrm{a}}\right)$ & $-0,0011 \pm(0,0029)$ \\
\hline Залишкове стандартне відхилення, $\mathrm{S}_{\text {x,o }}$ & 0,00571 \\
\hline Коефріцієнт кореляції, r & 0,9999 \\
\hline
\end{tabular}

Таблиця 3. Визначення збіжності результатів кількісного визначення дилтіазему в таблетках

\begin{tabular}{|l|c|c|c|c|}
\hline \multicolumn{1}{|c|}{ Лікарська фрорма } & $\widetilde{\widetilde{O}}_{(\mathrm{n}=9)}$ & $\mathrm{S}$ & $\mathrm{RSD}$ & $\Delta_{\text {× }}$ \\
\hline «Діакордін 60» & 0,0603 & $1,05 \cdot 10^{-4}$ & 0,174 & $1,95 \cdot 10^{-4}$ \\
\hline «Діакордін 90 Ретард» & 0,0896 & $1,50 \cdot 10^{-5}$ & 0,167 & $2,79 \cdot 10^{-4}$ \\
\hline
\end{tabular}

Таблиця 4. Визначення правильності результатів кількісного визначення дилтіазему в таблетках

\begin{tabular}{|l|c|c|c|c|}
\hline \multicolumn{1}{|c|}{ Лікарська фрорма } & $\bar{Z}_{(\mathrm{n}=9)}$ & $\mathrm{S}$ & $\Delta_{\mathrm{z}}$ & \\
\hline «Діакордін 60» & 100,12 & 0,0883 & 0,164 & 0,12 \\
\hline «Діакордін 90 Ретард» & 99,86 & 0,104 & 0,193 & 0,14 \\
\hline
\end{tabular}

Було встановлено, що аналізовані розчини стабільні протягом щонайменше 40 хв, а додавання $\pm 10 \%$ реагенту не впливає на величину оптичної густини.

Висновки. У результаті роботи встановлено, що дилтіазем реагує з БКЗ у середовищі ацетону за кімнатної температури з утворенням забарвленого продукту з максимумом світлопоглинання при 408 нм.
Досліджувана реакція є високочутливою: молярний коефіцієнт світлопоглинання становить 11547, а відкривальний мінімум 1,79 мкг/мл.

Доведено, що за такими валідаційними характеристиками, як лінійність, прецизійність, правильність та робасність розроблена методика є коректною і може бути використана у відділах технічного контролю хіміко-фрармацевтичних підприємств.

ISSN 2312-0967. Фармацевтичний часопис. 2017. № 4 


\title{
РАЗРАБОТКА И ВАЛИДАЦИЯ МЕТОДИКИ СПЕКТРОФОТОМЕТРИЧЕСКОГО КОЛИЧЕСТВЕННОГО ОПРЕДЕЛЕНИЯ ДИЛТИАЗЕМА В ЛЕКАРСТВЕННЫХ ФОРМАХ
}

\author{
М. И. Сулыма ${ }^{1}$, В. В. Огурцов ${ }^{1}$, Ю. М. Жук², С. А. Васюк² \\ Львовский национальный медицинский университет имени Данила Галицкого ${ }^{1}$ \\ Запорожский государственный медицинский университет ${ }^{2}$ \\ Sumarta145@gmail.com
}

Цель работы. Разработка методов контроля качества, в частности, спектрофотометрического определения количественного содержания дилтиазема в лекарственных фрормах «Диакордин 60» и «Диакордин 90 ретард» на основе реакции с бромкрезоловый зеленым, а также валидация разработанных методик.

Материалы и методы. Объекты исследования - таблетки «Диакордин 60» (Zentiva в составе САНОФИ, Чешская Республика, серия 3010117) и таблетки «Диакордин 90 ретард» (Zentiva в составе САНОФИ, Чешская Республика, серия 3510317).

Реагенты и растворители: стандартный образец дилтиазема, бромкрезоловый зеленый, ацетон.

Аналитическое оборудование: спектрофотометр Specord 200, весы электронные ABT-120-5DM, ультразвуковая баня ELMASONICE60 H.

Результаты и обсуждение. Разработана методика спектрофотометрического определения количественного содержания дилтиазема в лекарственных фрормах «Диакордин 60» и «Диакордин 90 Ретард» на основе реакции с бромкрезоловый зеленым. Стехиометрические соотношения реагирующих компонентов «дилтиазем - БКЗ», полученные методами непрерывных изменений и методом насыщения полностью согласуются между собой и составляют 1:1. По таким валидационным характеристикам, как линейность, прецизионность, правильность и робасность разработанная методика является корректной и может быть использована в отделах технического контроля химико-срармацевтических предприятий.

Выводы. В результате работы установлено, что дилтиазем реагирует с БКЗ в среде ацетона при комнатной температуре с образованием окрашенного продукта с максимумом светопоглощения при 408 нм. Исследуемая реакция является высокочувствительной: молярный коэфффициент светопоглощения составляет 11547, а открывающий минимум 1,79 мкг / мл.

Доказано, что по таким валидационным характеристиками, как линейность, прецизионность, правильность и робастность разработанная методика является корректной и может быть использована в отделах технического контроля химико-фрармацевтических предприятий.

Ключевые слова: дилтиазем; бромкрезоловый зеленый; ацетон; спектрофротометрическое определение.

\section{METHOD DEVELOPMENT AND VALIDATION OF DILTIAZEM IN PHARMACEUTICAL FORMS BY SPECTROPHOTOMETRIC QUANTITATIVE DETERMINATION}

\author{
M. I. Sulyma ${ }^{1}$, V. V. Ogurtsov ${ }^{1}$, Yu. M. Zhuk², S. O. Vasyuk ${ }^{2}$ \\ Danylo Halytsky Lviv National Medical University ${ }^{1}$ \\ Zaporizhzhia State Medical University² \\ Sumarta145@gmail.com
}

The aim of the work. Development of quality control methods, in particular, spectrophotometric determination of the quantitative content of diltiazem in the dosage forms «Diacordin 60» and «Diacordin 90 retard» on the basis of the reaction with bromocresol green, as well as validation of the developed methods.

Materials and Methods. The research objects are tablets «Diacordin 60» (Zentiva in SANOFI, Czech Republic, series 3010117) and tablets «Diacordin 90 Retard» (Zentiva in SANOFI, Czech Republic, series 3510317).

Reagents and solvents: A standard sample of diltiazem, bromocresol green, acetone.

Analytical equipments: Spectrophotometer Specord 200, electronic scalesAVT-120-5DM, ultrasonic bath ELMASONICE60 H. Results and Discussion. The technique of spectrophotometric determination of the quantitative content of diltiazem in the dosage forms «Diacordin 60» and «Diacordin retard 90» based on the reaction with bromocresol green was developed. The stoichiometric ratios of the reactive components «diltiazem-BKG», obtained by the methods of continuous changes and the saturation method, completely agree with each other and amount 1:1. Based on such validation characteristics as linearity, precision, accuracy and robustness, the technique is correct and can be used in technical departments control of chemical and pharmaceutical enterprises.

ISSN 2312-0967. Pharmaceutical review. 2017. № 4 
Conclusions. As a result of the work, it was found that diltiazem reacts with BKG in an acetone medium at room temperature to form a colored product with a maximum absorption at $408 \mathrm{~nm}$. The investigated reaction is highly sensitive: the molar absorption coefficient is 11547, and the opening minimum is $1.79 \mu \mathrm{g} / \mathrm{ml}$.

It is proved that the methodology developed by such validation characteristics as linearity, precision, correctness and robustness is correct and can be used in the departments of technical control of chemical and pharmaceutical enterprises.

Key words: diltiazem; bromocresol green; acetone; spectrophotometric determination.

\section{Список літератури}

1. Devarajan P. V. High-performance thin-layer chromatographic determination of diltiazem hydrochloride as bulk drug and in pharmaceutical preparations / P. V. Devarajan, V. V. Dhavse // J. Chromatogr., B: Biomed. Appl. - 1998. Vol. 706. - P. 362-366.

2. Sultana N. A validated method for the analysis of Diltiazem in raw materials and pharmaceutical formulations by RP-HPLC Pak / N. Sultana, M. S. Arayne, N. Shafi // J. Pharm. Sci. - 2007. - Vol. 20. - P. 279-284.

3. Analysis of diltiazem and its related substances by HPLC and HPLC/MS / M.G. Quaglia, E. Donati, S. Fanali [et al.] // J. Pharm. Biomed. Anal. - 2005. - Vol. 37. - P. 695-701. 4. Development and validation of assay method by RP-HPLC for determination of diltiazem hydrochloride active pharmaceutical ingredient / Ramchandra Krishna Pawar, Ram Lokhande, Ravi Yadav [et al.] // International Journal of Chemical and Pharmaceutical Analysis. - 2017. - Vol. 4, №2.

5. Akram El-Didamony M. Indirect spectrophotometric determination of diltiazem hydrochloride in pure form and pharmaceutical formulations / M. Akram El-Didamony // Central European Sci. J. - 2005. - Vol. 3, №3. - P. 520-536. 6 . New colorimetric methods for the determination of trazodone $\mathrm{HCl}$, famotidine, and diltiazem $\mathrm{HCl}$ in their pharma- ceutical dosage forms / Magda M. Ayad, Abdalla Shalaby, Hisham E. Abdellatef [et al.] // Analytical and Bioanalytical Chemistry. - 2003. - Vol. 376, №5. - P. 710-714.

7. Nafisur Rahman Syed. Extractive spectrophotometric methods for determination of diltiazem $\mathrm{HCl}$ in pharmaceutical formulations using bromothymol blue, bromophenol blue and bromocresol green / Nafisur Rahman Syed, Najmul Hejaz-Azmi // Journal of Pharmaceutical and Biomedical Analysis. - 2000. - Vol. 24, №1. - P. 33-41.

8. Kamath B. V. Selective spectrophotometric determination of diltiazem hydrochloride in tablets / B. V. Kamath, K. Shivram, A. C. Shah // Journal of Pharmaceutical and Biomedical Analysis. - 1993. - Vol. 11, №4-5. - P. 407-409. 9. Nafisur Rahman Syed. Spectrophotometric determination of diltiazem hydrochloride with sodium metavanadate / Nafisur Rahman Syed, Najmul Hejaz Azmi // Microchemical Journal. - 2000. - Vol. 65, №1. - P. 39-43.

10. Булатов М. И. Практическое руководство по сотометрическим методам анализа - 5-е изд. / М. И. улатов, И. П. Калинкин. - Л. : Химия, 1986. - 432 с. 11. Державна Фармакопея України. - 1-е вид. - Харків : Державне підприємство «Науково-експертний фрармакопейний центр», 2008. - Доповнення 2. - 2008. - 620 с.

\section{References}

1. Devarajan PV, Dhavse VV. High-performance thin-layer chromatographic determination of diltiazem hydrochloride as bulk drug and in pharmaceutical preparations. J Chromatogr B: Biomed Appl. 1998;706: 362-6.

2. Sultana N, Arayne MS, Shafi N A validated method for the analysis of Diltiazem in raw materials and pharmaceutical formulations by RP-HPLC Pak J Pharm Sci. 2007;20: 279-84.

3. Quaglia, MG, Donati E, Fanali S, et al. Analysis of diltiazem and its related substances by HPLC and HPLC/MS. J Pharm Biomed Anal. 2005;37: 695-701.

4. Ramchandra Krishna Pawar, Ram Lokhande, Ravi Yadav, et al. Development and validation of assay method by RP-HPLC for determination of diltiazem hydrochloride active pharmaceutical ingredient. International Journal of Chemical and Pharmaceutical Analysis. 2017;4(2).

5. M. Akram El-Didamony. Indirect spectrophotometric determination of diltiazem hydrochloride in pure form and pharmaceutical formulations. Central European Sci J. 2005;3(3): 520-36.

6. Magda M Ayad, Abdalla Shalaby, Hisham E Abdellatef et al. New colorimetric methods for the determination of trazodone $\mathrm{HCl}$, famotidine, and diltiazem $\mathrm{HCl}$ in their phar-

maceutical dosage forms. Analytical and Bioanalytical Chemistry. 2003;376(5): 710-14

7. Nafisur Rahman Syed, Najmul Hejaz-Azmi. Extractive spectrophotometric methods for determination of diltiazem $\mathrm{HCl}$ in pharmaceutical formulations using bromothymol blue, bromophenol blue and bromocresol green. Journal of Pharmaceutical and Biomedical Analysis. 2000;24(1): 33-41.

8. Kamath BV, Shivram K, Shah AC. Selective spectrophotometric determination of diltiazem hydrochloride in tablets. Journal of Pharmaceutical and Biomedical Analysis. 1993;11(4-5): 407-9.

9. Nafisur Rahman Syed, Najmul Hejaz Azmi. Spectrophotometric determination of diltiazem hydrochloride with sodium metavanadate. Microchemical Journal. 2000;65(1): 39-43.

10. Bulatov MI, Kalinkin IP. Practical guide on photometric methods of analysis. 5 ed. [Практическое руководство по фотометрическим методам анализа - 5-е изд.]Lviv: Chemistry; 1986. Russian.

11. State Pharmacopoeia of Ukraine. [Державна фрармакопея України] Kharkiv: Ukrainian Scientific Pharmacopoeia Center of Quality of Medicinal Products. 2 ed. X; 2008. Ukrainian. 